\title{
Genetic Algorithm for Dynamic Berth Allocation Problem with Discrete Layout
}

\author{
Tong Shan \\ School of Transportation and Logistics \\ Southwest Jiaotong University \\ Chengdu China ,610031 \\ tongshan1987@163.com
}

\begin{abstract}
Genetic Algorithm which is based on the Darwinian principle of natural selection has been successfully applied to Berth allocation problem (BAP), which can decide the ships' berthing position and berthing time at a container terminal. Considering the service priority, handing time deciding variables, safety clearance, as well as the berths' physical conditions, a dynamic berth allocation with discrete layout optimization model aimed at minimizing the total service time with the ships service priority considered at the port is proposed, and a genetic algorithm is applied to solve it. Numerical experiment is conducted and shows that the genetic algorithm performs well, and is useful to the container terminal management and can save a lot of resources.
\end{abstract}

Keywords- Genetic algorithm;Berth Allocation Problem; Optimization model; Container transportation

\section{INTRODUCTION}

Berth is one of the most important resources in the container port, the efficient management of it is essential to the port's profit. The berth allocation problem in the container port, which is short for BAP, is to assign a berthing position and a berthing time to every ship at a container terminal, according to (Imai et al. 2005), it can be divided into discrete and continuous layout, In the discrete case only one ship can be served at each single berth at a times; in the continuous case, the quay is regarded as a continuous line and the ships can be moored in any position along the quayside. When considering the ships' arrival time, the static arrival and dynamic arrival are distinguished (Imai et al. 2001), all the ships are already at the port and can berth immediately is considered by the static case, otherwise, if not all of the ships are at port when the berthing plan is making, it is the dynamic case.

There are some related studies dealing with the berth allocation problem outboard and inboard, Imai et al. propose a dynamic berth allocation problem, and use the heuristic procedure based on the Lagrangian relaxation to solve it [1]. Imai et al. considered service priority of the existing formulation of the berth allocation problem and a genetic algorithm based heuristic is presented to solve the non-linear problem [2]. Motivated by the fact not all of the ships are moored with the boundary of berth, Imai et al. present a heuristic for the berth allocation problem in continuous locations, the objective of the modeling is to minimize the total service time where the ship's handing time depends on the ship's berthing location in the quay [3]. Monaco et al. analyze the properties of the discrete berth with dynamical arrival, and develop a Lagrangean heuristic algorithm [4]. Theofanis et al. present an optimization model based on Genetic Algorithm heuristic for discrete and dynamic BAP aimed at minimizing the total weighted service time of all the ships [5]. LI Ping proposes a dynamic berth allocation model considering the operability of practical operation and combining with actual operation situation of container terminals, also takes the ships service priority into consideration, and an improved generalized genetic algorithm is designed [6].

In this paper, we propose a model for berth allocation problem based on the previous study in TONG Shan et al.2011[7], service priority, handing time deciding variables, safety clearance, as well as the berths' physical conditions, are simultaneously considered, and an optimization berth allocation model is proposed, which is more practical than previous studies.

\section{OPTIMIZATION MODEL}

In order to take the actual situation into consideration, service priority is considered in this paper, rather than follow the FCFS service rule, and it is decided by the handling volumes of every ship. Also, the safety clearance is discussed, which is decided according to the ships' length as Tab. 1. The handling time, which is decided according to the equation in paper [8], is affected by a lot of factors, among which the following are the most important and be considered in this paper: the number of containers to be handled, the number of yard-trailers hauling containers between a quay crane and container stack on the yard, the distance between the quay crane and container stack and the ship category is defined by Tab. 2 .

In order to formulate the optimization model, the following notations are discussed. The notation we use is based on the study of TONG Shan et al. [7], That is, $i(=1, \cdots, T) \in B$ : set of berths; $j(=1, \cdots, T) \in V$ : set of ships. $k(=1, \cdots, T) \in O$ : set of service orders; $P_{k}$ : subset of $O_{\text {so that }} P_{k}=\{p \mid p<k \in O\} ; W_{i}$ : subset of ships with $a_{j} \geq S_{i} ; S_{i}$ : time when berth i becomes idle for the berth allocation planning; ${ }^{L_{i}}$ : length of berth i , ${ }^{i}$ : water depth of berth $\mathrm{i} ;{ }^{a_{j}}$ : estimated arrival time of ship $\mathrm{j} ;{ }^{\alpha_{j}}$ : the number of containers to be handled of ship $\mathrm{j} ;{ }^{\beta_{i}}$ : the number 
of yard-trailers hauling containers between a quay crane and container stack on the yard; $\gamma_{i}$ : the distance between the quay crane and container stack; $\mathcal{E}$ : the affect factor which is adopted to measure the handling volume's influence to the berth allocation, the larger $\mathcal{E}$ is, the bigger the influence would be; ${ }^{p_{j}}$ : the service priority of ship $\mathrm{j} ;{ }^{l}$ : length of ship $\mathrm{j} ;{ }^{l}$ : safety clearance of ship $\mathrm{j} ;{ }^{d}{ }_{j}$ : draft of ship $\mathrm{j}$; $C_{i j}$ : handling time of ship $\mathrm{j}$ at berth $\mathrm{i} ;{ }^{x_{i j k}}: 1$ if ship $\mathrm{j}$ is

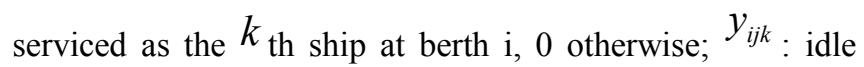
time of berth i between the departure of the $k-1_{\text {th ship and }}$

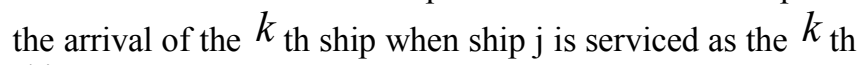
ship.

The optimization model is as follows which aimed at minimizing total service time with service priority.

$$
\begin{aligned}
& \sum_{i \in B} \sum_{j \in V} \sum_{k \in O}\left\{(T-k+1) C_{i j}+S_{i}-a_{j}\right\} p_{j} x_{i j k}+\sum_{i \in B} \sum_{j \in W_{i} k \in O}(T-k+1) p_{j} y_{i j k} \\
& \sum_{i \in B} \sum_{k \in O}^{\text {s.t. }} x_{i j k}=1 \quad \forall j \in V \\
& \sum_{j \in V} x_{i j k} \leq 1 \quad \forall i \in B, k \in O \\
& \sum_{l \in V} \sum_{m \in P_{k}}\left(C_{i l} x_{i l m}+y_{i l m}\right)+y_{i j k}-\left(a_{j}-S_{i}\right) x_{i j k} \geq 0 \quad \forall i \in B, j \in W_{i}, k \in O \\
& C_{i j}=0.75 \alpha_{j}-0.77 \beta_{i}+0.29 \gamma_{i}+1.71 \quad \forall i \in B, j \in V, k \in O \\
& p_{j}=1-\varepsilon / \alpha_{j} \quad \forall j \in V \\
& \sum_{k \in O}\left(L_{i}-l_{j}-l_{j}^{\prime}\right) x_{i j k} \geq 0 \quad \forall i \in B, j \in V \\
& \sum_{k \in O}\left(D_{i}-d_{j}\right) x_{i j k} \geq 0 \quad \forall i \in B, j \in V \\
& x_{i j k} \in\{0,1\} \quad \forall i \in B, j \in V, k \in O \\
& y_{i j k} \geq 0 \quad \forall i \in B, j \in V, k \in O
\end{aligned}
$$

The objective of this formulation is to minimize the total service time of all ships with the consideration of ships service priority, and its handling time is decided by some essential factors. Constraints (2) enforce that every ship must be serviced in only one berth. Constraints (3) ensure that every berth services one ship at any time at most. Constraints (4) show that ships can't be serviced before their arrival. Constraints (5) give the definition of the handling time of ship $\mathrm{j}$ at berth $\mathrm{i}$, which is decided according to the equation of (Imai, A.,2007) [8],Constraints (6) give the definition of the ships' service priority, which has direct proportion to the handling volume, that is, the more containers to be handled in the ship, the higher priority the ships have. Constraints (7) ensure that the length of every ship with consideration of the safety clearance can't exceed the length of the berth. Constraints (8) take the water depth of the berth and draft of ship into consideration. Constraints (9) and (10) are the definitional domain of corresponding variables.
Although the formulation is linear, it is complicated and not likely that an efficient exact solution method exists, therefore, in order to solve the solution procedure, a GAbased heuristic is provided in next section, but for the small one, it can be solve efficiently by some commercial software.

\section{GENETIC ALGORITHM}

Based on the Darwinian principle of natural selection, the genetic algorithm learning model was initially developed by Holland (1975) and Genetic programming has been successfully applied to problems that are difficult to solve using traditional methods. Theofanis, S. et al. 2007[5], Nishimura, E. et al. [9] and TONG Shan et al.[7] use genetic algorithm to solve this problem, but their model of BAP is different, based on their study, the application of GA to BAP model of this paper is as follows:

Step 0: Chromosome coding. An integer chromosomal representation is used to exploit in the full characteristics of the problem. Every gene in the chromosome represents the number of ships. The length of the chromosome string is the number of ships plus the number of berths minus one, where sets of ships allocated to berths are separated by zeros. Ships allocated to a specific berth are placed in order of berthing from left to right.

Step 1: To generate the initial population randomly. According to the given scales of the population and to obtain the initial population randomly, that is, to generate a full collocate of $\mathrm{j}$ ships, randomly choose $i-1$ points in the interval $[1, j-1]$, the insert a " 0 " in every point, so the initial chromosome coding is acquired, which shows the initial berth allocation planning, repeat such steps, and check the diversity of the population, to ensure that every individual is the unique one, until the population scale is up to the set value.

Step 2: to calculate the fitness degree of the individuals, and distinguish whether them are satisfied the optimization rule, if satisfied, then STOP and export the best individual; otherwise, go to Step 4. And the optimization model in this paper is a minimization problem, thus, the smaller the objective function value is, the higher the fitness value must be. In such a case, the fitness function could be defined as the reciprocal of the objective function. In order to ensure the value of this function is to be in the reasonable section, exponential switch is adopted. So the fitness function is as follows:

$$
f(x)=\frac{1}{(1+\exp (y(x) / 10000))} .
$$

And the optimization rule is that the average fitness value exceeds the set value.

Step 3: According to the fitness value of the individuals, the roulette wheel selection is used to select the chromosomes as parents. The individuals with high fitness value are likely to be selected, as to the individuals with low fitness value; it is more likely to remove away.

Step 4: To use the two-point crossover method, the crossover ratio usually ranges from 0.1 to 0.5 . 
Step 5: To reverse the mutation, the mutation ratio usually ranges from 0.001 to 0.005 .

Step 6: To protect the best individuals, use the current best individuals replace the worst, then generate a new population, and go to step 2 .

\section{NUMERICAL EXAMPLE}

Taking a port district with 5 berths as an example, a basic problem in which 10 ships are served at the district with various handling volumes is developed. Also the safety clearance is calculated according to the Tab. 1. The information of every berth and ship are respectively given in Tab. 3 and Tab. 4 as follows.

The distance between the quay crane and container stack is assumed to be the same value, which is $100 \mathrm{~m}$, so the handling time is calculated according to the formula (5). Also assume each berth is available at time 0 .

The problem is coded in LINGO11.0 on a personal computer with Dual CPU $1.80 \mathrm{GHz} \&$ RAM 1G. And an optimal solution is found in half a minute, we can know where and when the ships should be berth: in berth 1, after waiting for 23 hours, ship 10 is firstly moored and then ship 8 ; in berth 2 , ship 1 is immediately moored and then ship 3; in berth 3, after waiting for 2 hours, ship 2 is moored and then ship 6; in berth 4 , ship 7 is moored after waiting for 13 hours and the ship 4 is moored; in berth 5 , ship 5 is moored after waiting for 9 hours and then ship 9 is moored. The total service time is 6120.241 hours, which is including handling time and waiting time.

\section{CONCLUSION}

Compared with previous studies about BAP, this optimization model in this paper is more practical by simultaneously considering service priority, safety clearance, the berths' physical conditions, as well as handing time deciding variables such as the number of containers to be handled, the number of yard-trailers hauling containers between a quay crane and container stack on the yard, the distance between the quay crane and container stack, a dynamic berth allocation with discrete layout optimization model aimed at minimizing the total service time with the consideration of service priority at the port is proposed, where the total service time include the waiting time and handling time, and this optimization model in this paper is solved by the proposed Genetic Algorithm, which was proved to be effective and could find a better solution.

\section{REFERENCES}

[1] Imai, A., Nishimura, E., Papadimitriou, S.,(2001). The dynamic berth allocation problem for a container port. Transportation Research Part B 35 (4), 401-417.

[2] Imai, A., Nishimura, E., Papadimitriou, S., (2003). Berth allocation with service priority. Transportation Research Part B 37 (5), 437-457.

[3] Imai, A., Sun, X., Nishimura, E., Papadimitriou, S.,(2005). Berth allocation in a container port: Using a continuous location space approach. Transportation Research Part B 39, 199-221.

[4] Monaco, M., Sammarra, M., (2007). The berth allocation problem: a strong formulation solved by a Lagrangian approach. Transportation Science 41 (2), 265-280.

[5] Theofanis, S., Boile, M., Golias, M., (2007). An Optimization Based Genetic Algorithm Heuristic for the Berth Allocation Problem. IEEE Congress on Evolutionary Computation(CEC 2007),4439-4445.

[6] LI Ping, SUN Junqing, HAN Mei (2006). The algorithm for the berth scheduling problem by the hybrid optimization strategy GATS. Journal of TianJin University of Technology 22(4), 58-61.

[7] TONG Shan, ZHAO Jun (2011). A Time-space Diagram for Solving Dynamic Berth Allocation Problem at Container Terminal. 2011 International Conference on Transportation Engineering.116.

[8] Imai, A., Nishimura, E., Hattori, M., Papadimitriou, S., (2007). Berth allocation at indented berths for mega-containerships. European Journal of Operational Research 179 (2), 579-593.

[9] Nishimura,E., Akio Imai,A.,Papadimitriou,S..(2001).Berth allocation planning in the public berth system by genetic algorithms. European Journal of Operational Research 131,282-292.

TABLE I. SHIPS' LENGTH AND SHIP'S SAFETY CLEARANCE RELATIONSHIP (UNIT: METERS)

\begin{tabular}{|c|c|c|c|c|c|c|}
\hline ships' length & $<\mathbf{4 0}$ & $\mathbf{4 1} \mathbf{8 5}$ & $\mathbf{8 6} \sim \mathbf{1 5 0}$ & $\mathbf{1 5 1} \mathbf{2 0 0}$ & $\mathbf{2 0 1} \sim \mathbf{2 3 0}$ & $>\mathbf{2 3 0}$ \\
\hline $\begin{array}{c}\text { safety } \\
\text { clearance }\end{array}$ & 5 & $8 \sim 10$ & $12 \sim 15$ & $18 \sim 20$ & $22 \sim 25$ & 30 \\
\hline
\end{tabular}

TABLE II. SHIP CATEGORY

\begin{tabular}{|c|c|c|}
\hline Ship length & Number of containers handled & Number of quay cranes \\
\hline $50-99$ & $50-300$ & 1 \\
\hline $100-149$ & $301-600$ & 2 \\
\hline $150-200$ & $601-900$ & 3 \\
\hline
\end{tabular}

TABLE III. BERTH INFORMATION OF PORT DISTRICT

\begin{tabular}{|c|c|c|c|c|c|}
\hline Berth & Berth 1 & Berth 2 & Berth 3 & Berth 4 & Berth 5 \\
\hline Length of berth $(\mathrm{m})$ & 220 & 200 & 200 & 200 & 220 \\
\hline Water depth of berth $(\mathrm{m})$ & 12 & 12 & 12 & 12 & 12 \\
\hline
\end{tabular}


TABLE IV. CONTAINER SHIP INFORMATION

\begin{tabular}{|c|c|c|c|c|c|c|}
\hline Ship & $\begin{array}{c}\text { Estimated } \\
\text { arrival time } \\
(\mathbf{h})\end{array}$ & $\begin{array}{c}\text { Handling } \\
\text { volumes } \\
\text { (TEU) }\end{array}$ & $\begin{array}{c}\text { Length of ship } \\
\text { (m) }\end{array}$ & $\begin{array}{c}\text { Safety } \\
\text { clearance (m) }\end{array}$ & $\begin{array}{c}\text { Number of } \\
\text { quay cranes }\end{array}$ & $\begin{array}{c}\text { Draft of ship } \\
\text { (m) }\end{array}$ \\
\hline Ship 1 & 0 & 300 & 90 & 15 & 1 & 8.5 \\
\hline Ship 2 & 2 & 350 & 95 & 15 & 1 & 8.6 \\
\hline Ship 3 & 4 & 700 & 175 & 20 & 3 & 10 \\
\hline Ship 4 & 7 & 650 & 170 & 20 & 2 & 9.5 \\
\hline Ship 5 & 9 & 500 & 140 & 15 & 2 & 9 \\
\hline Ship 6 & 11 & 800 & 180 & 20 & 3 & 10.3 \\
\hline Ship 7 & 13 & 400 & 100 & 15 & 2 & 8.8 \\
\hline Ship 8 & 17 & 900 & 200 & 20 & 3 & 12 \\
\hline Ship 9 & 20 & 850 & 190 & 20 & 3 & 11.5 \\
\hline Ship 10 & 23 & 300 & 90 & 15 & 1 & 8.5 \\
\hline
\end{tabular}

